\title{
Regadenoson cardiovascular magnetic resonance myocardial perfusion imaging predicts need for future revascularization
}

\author{
Benjamin H Freed ${ }^{1 *}$, Kristen M Turner ${ }^{2}$, Chattanong Yodwut ${ }^{3}$, Giacomo Tarroni ${ }^{4}$, Emily Estep ${ }^{1}$, Nicole M Bhave ${ }^{1}$, \\ Akhil Narang ${ }^{1}$, Sara Tanaka ${ }^{1}$, Cristiana Corsi ${ }^{4}$, Etienne Gayat ${ }^{1}$, Peter Czobor ${ }^{1}$, Kevin Cavanaugh ${ }^{1}$, Roberto Lang ${ }^{1}$, \\ Victor Mor-Avi ${ }^{1}$, Amit R Patel ${ }^{1}$
}

From 15th Annual SCMR Scientific Sessions

Orlando, FL, USA. 2-5 February 2012

\section{Summary}

Regadenoson is a new vasodilator myocardial stress agent that is easier-to-use and more tolerable than adenosine. We demonstrate that, in patients undergoing cardiovascular magnetic resonance myocardial perfusion imaging, regadenoson is safe and effective in producing hyperemia and identifying the need for future revascularization.

\section{Background}

Regadenoson (Lexiscan; Astellas) is a new vasodilator myocardial stress agent that selectively activates the A2A receptor. Unlike adenosine, regadenoson is easier to administer and results in fewer side effects. Although extensively studied in patients undergoing nuclear myocardial perfusion imaging (MPI), its performance in cardiovascular magnetic resonance (CMR) MPI remains unknown. The aim of this study was to assess the safety and tolerability of regadenoson and determine its ability to produce hyperemia and predict subsequent coronary revascularization in patients undergoing CMR-MPI.

\section{Methods}

120 patients were prospectively enrolled to receive CMR-MPI (Achieva, Philips 1.5T) with regadenoson. Patients with contraindications to CMR-MPI or regadenoson were excluded. Short-axis slices were obtained at three levels of the left ventricle (LV) during first pass of Gadolinium-DTPA $(0.075 \mathrm{mmol} / \mathrm{kg}$ at $4 \mathrm{ml} / \mathrm{sec})$ for 50 consecutive heart beats. Images were acquired using a

${ }^{1}$ Internal Medicine, University of Chicago Medical Center, Chicago, IL, USA Full list of author information is available at the end of the article hybrid gradient echo/echo planar imaging sequence. Imaging was performed 1 minute after injection of regadenoson $(0.4 \mathrm{mg})$ and then repeated 15 minutes after injection of aminophylline $(125 \mathrm{mg})$ under resting conditions. Perfusion defects were defined as subendocardial hypointensity in a coronary distribution at stress, involving $\geq 25 \%$ wall thickness, and persisting for $\geq 2$ heart beats following peak enhancement of the LV cavity. In a subgroup of patients $(n=99)$, custom software was used to generate time intensity curves and to compare the myocardial upslope of the midventricular slice during stress and rest. All subjects were followed for 3 months for the occurrence of coronary revascularization.

\section{Results}

Overall, 51/120 (43\%) of patients were female with an average age of $55 \pm 15$ years and body mass index of 29 $\pm 6 \mathrm{~kg} / \mathrm{m} 2$. Baseline patient characteristics include: coronary artery disease $(33 \%)$, diabetes $(38 \%)$, hypertension (56\%), and hypercholesterolemia (95\%). The average resting blood pressure and heart rate were 124/ $61 \mathrm{mmHg}$ and $70 \mathrm{bpm}$, respectively. Peak heart rate after regadenoson administration was $98 \mathrm{bpm}(\mathrm{p}<0.001)$. Most patients (87\%) experienced side effects from regadenoson including shortness of breath (34\%), flushing (23\%), and chest discomfort (17\%). No EKG changes or residual side effects persisted in any patient at completion of study. The average myocardial upslope increased significantly between rest and stress conditions $(9.1 \pm 5.9$ vs. $12.8 \pm 8.1, \mathrm{p}<0.001)$, reflecting the expected hyperemic effect of regadenoson. Perfusion defects were visually apparent in 33/120 (28\%) patients. Revascularization occurred in 8/120 (7\%) patients (Figure 1). The presence 

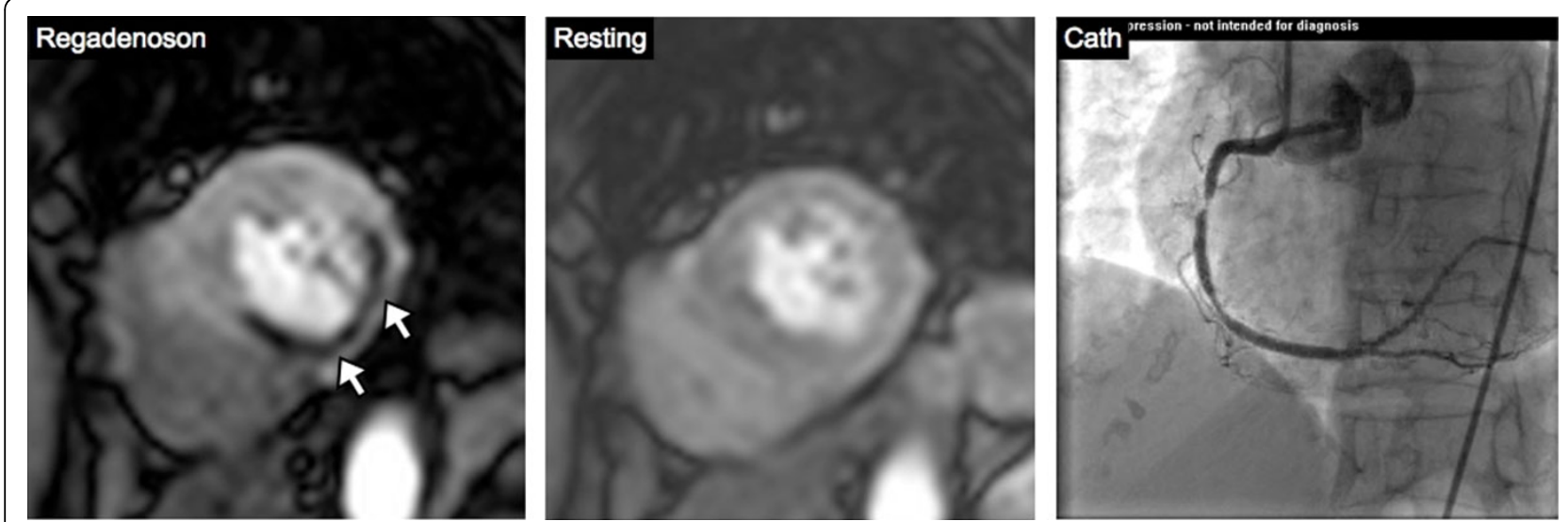

Figure 1 Patient with perfusion defect in inferior and inferior-lateral myocardial wall undergoing regadenoson CMR-MPI and subsequent cardiac catheterization of right coronary artery.

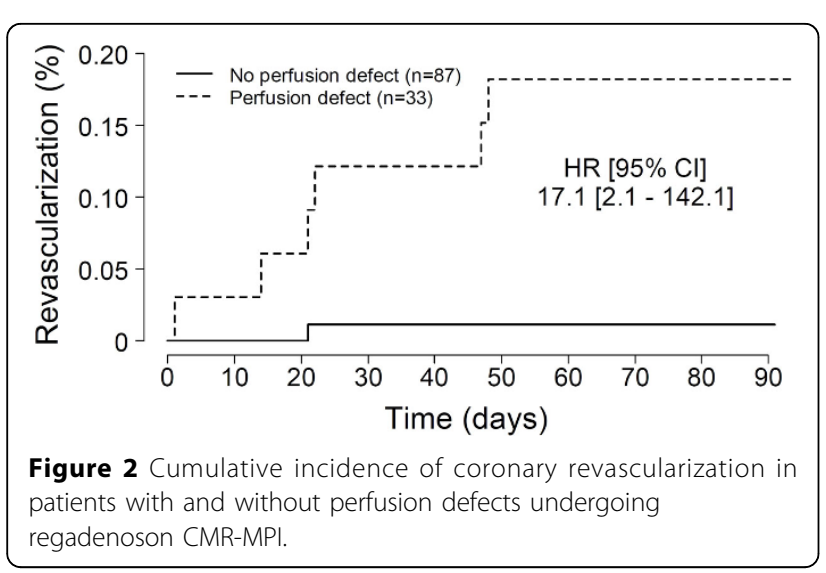

of a perfusion defect significantly predicted future revascularization (Figure 2). Only 1 patient without a perfusion defect was revascularized within the follow-up period.

\section{Conclusions}

Regadenoson is safe, easy-to-use, and effective in producing hyperemia and identifying need for future revascularization in patients undergoing CMR-MPI.

\section{Funding}

Research was funded in part by a research grant from Astellas Pharmaceutical.

\section{Author details}

${ }^{1}$ Internal Medicine, University of Chicago Medical Center, Chicago, IL, USA.

${ }^{2}$ Internal Medicine, Loyola Medical Center, Maywood, IL, USA. Internal Medicine, Ramathibodi Hospital, Mahidol University, Bangkok, Thailand.

${ }^{4}$ University of Bologna, Bologna, Italy, USA.
doi:10.1186/1532-429X-14-S1-P7

Cite this article as: Freed et al:: Regadenoson cardiovascular magnetic resonance myocardial perfusion imaging predicts need for future revascularization. Journal of Cardiovascular Magnetic Resonance 201214 (Suppl 1):P7.
Submit your next manuscript to BioMed Central and take full advantage of:

- Convenient online submission

- Thorough peer review

- No space constraints or color figure charges

- Immediate publication on acceptance

- Inclusion in PubMed, CAS, Scopus and Google Scholar

- Research which is freely available for redistribution 